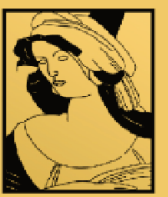

\title{
ALEXANDRIA
}

Revista de Educação em Ciência e Tecnologia

ALEXANDRIA

\section{Ciência, Opressão e Teatro: Um Caso de Pesquisa Educacional Baseada em Artes}

\section{Science, Oppression and Theatre: A Case Study of Art-based Educational Research}

\section{Leonardo M. Moreira"; Angélica S. do Nascimento ${ }^{a}$; Laise N. N. de Souza ${ }^{a}$}

a Campus Macaé, Universidade Federal do Rio de Janeiro, Macaé, Brasil - leo.qt@hotmail.com, angelsantana@hotmail.com, lalanovellino@hotmail.com

\section{Palavras-chave: Educação em ciências. Opressão. Teatro. Pesquisa educacional baseada em artes. Ensino superior.}

Resumo: A abordagem de temas controversos tem sido um caminho para evidenciar o vínculo entre ciência e contexto social, favorecendo a educação CTS. Esta pesquisa tem como objetivo identificar e caracterizar as percepções de um grupo de estudantes universitários sobre o tema controverso: relações entre ciência e opressão. O método utilizado foi a pesquisa educacional baseada em artes, adotando o Teatro do Oprimido como linguagem artística. Encontrou-se que, na percepção dos colaboradores, a ciência pode ser utilizada para oprimir e que a opressão por meio da ciência é caracterizada por similaridades com opressões impostas pelo mundo do trabalho, pela mídia e pelo sistema de educação. Os resultados sugerem que a discussão do tema ciência e opressão favorece o conhecimento sobre a ciência, podendo resultar em atitudes positivas para com ela, e sinalizam a proficuidade da pesquisa educacional baseada em artes para a educação em ciências

\section{Keywords:}

Science education. Oppression. Theatre. Art-based educational research. College education.
Abstract: The controversial themes has been a way to highlight the link between science and social context to achieve scientific literacy. The aim of this research is to identify and characterize the perceptions of a group of university students about the controversial topic: relations between science and oppression. The method used was arts-based educational research, adopting the Theater of the Oppressed as artistic language. From collaborator's perception, science can be used to oppress and the oppression through science is characterized by similarities with oppressions imposed by the work, the media and the education system. The results suggest discussions of science and oppression result knowledge growth about science and may result in positive attitudes towards science. And shows the profitability of artsbased educational research in science education. 


\section{Introdução}

Texto A abordagem de temas controversos tem tomado vulto no ensino de ciências. Um tema controverso é aquele que não pode ser resolvido somente com base em fatos e análises técnicas. Ele é caracterizado por envolver também valores, aspectos éticos e religiosos, pressões de grupos econômicos e sociais e idiossincrasias de determinada pessoa ou coletividades (SILVA; CARVALHO, 2007; REIS, 2009; REIS, SILVA; PINA, 2011). Alguns exemplos de temas controversos pertinentes ao ensino de ciências são as mudanças climáticas, as pesquisas com células tronco, a bioética e a relação entre ciência e opressão, dentre outros. A abordagem de temas controversos no ensino de ciências tem contribuído para a explicitação dos vínculos da ciência com o contexto social e tecnológico, e por proporcionar aos educandos o desenvolvimento de conhecimentos, competências e habilidades, pessoais e coletivas, e a prática da resolução racionalizada e crítica de problemas científicos (RAZERA; NARDI, 2006; REIS, 2009; MARTINS, 2015; BORGERDING; DAGISTAN, 2018). Esse tipo de abordagem encontra eco em propostas alinhadas com as perspectivas da Educação CTS (AULER, 2007; STRIEDERA; KAWAMURA, 2017; RIBEIRO et al., 2017).

Um tema controverso recorrente em debates a respeito da ciência é sua influência sobre a sociedade, sobre os sujeitos. A força que frases como comprovado cientificamente geram na população em geral, ou a assunção de que algo deva ser feito ou pensado sob determinada perspectiva porque a ciência assim o indicou, nos remete a reflexões sobre o quanto a ciência pode oprimir ou libertar mentes e corpos. A percepção da ciência como opressora ou como libertadora pode ter impacto no envolvimento de estudantes com ciência e com a prática científica, com implicações para sua aprendizagem, conforme explicam Pozzo e Crespo (2009) ao argumentarem que parte da resistência de estudantes a aquisição de conhecimentos científicos está relacionada a um conflito entre a cultura do estudante e a cultura científica. Assim, o conhecimento da percepção de estudantes quanto a caracterização da ciência como opressora ou libertadora e das ideias que se encadeiam às percepções possui importância para o ensino de ciências, podendo auxiliar na construção de perspectivas em que a ciência e o conhecimento científico sejam reconhecidos como caminhos para a libertação de oprimidos.

Neste contexto, esta pesquisa problematiza o tema controverso ciência e opressão e tem como objetivo identificar e caracterizar as percepções de um grupo de estudantes universitários sobre as relações entre ciência e opressão. A investigação qualitativa realizada teve como mote a questão: Quais são as relações existentes entre ciência e opressão na perspectiva dos colaboradores? No cenário teórico em que a pesquisa foi desenvolvida foi adotado o conceito de opressão conforme desenvolvido por Paulo Freire $(1976,1987,1994)$ e a leitura da ciência na perspectiva de Pierre Bourdieu (1983, 2004). Por entender a 
importância de se aproximar o quanto possível da subjetividade envolvida na percepção dos colaboradores, foi adotada a metodologia denominada de pesquisa educacional baseada em artes (BARONE; EISNER, 1997), na qual a pesquisa científica se desenvolve permeada por uma abordagem estética. A linguagem artística elencada foi o teatro, especificamente o Teatro do Oprimido criado e difundido por Augusto Boal $(2008 ; 2013)$.

A articulação entre o teatro e a pesquisa e a educação em ciências já vem sendo bastante desenvolvida (MOREIRA; MARANDINO, 2015; REIS et al., 2019; CAMPANINI; ROCHA, 2019). Essa prática teatral é denominada de teatro de temática científica, ou teatro científico, e integra propostas teatrais que abordam tanto as ciências da natureza, quanto as ciências humanas, entre outras, seja como conteúdo conceitual, histórico, filosófico, cultural ou epistemológico, seja como inspiração artística. O teatro de temática científica (TTC) é um meio de se explicitar as relações entre ciências e tecnologias e seu contexto social, histórico, cultural e apresentar assuntos complexos ou controversos de forma inteligível e multifacetada, sendo utilizado em espaços de educação formal e de educação não formal. Apesar dos esforços em tipificá-lo (BARBACCI, 2002; CHEMI; KASSTBERG, 2015; MOREIRA; MARANDINO, 2015), sua diversidade varia desde espetáculos focalizando conceitos específicos das ciências até abordagens artísticas com inspiração em temas científicos e em seus conflitos. A proficuidade da relação entre teatro e ciência reside na possibilidade de se conhecer a ciência para além dos seus conceitos ou experimentos, focalizando uma abordagem mais humanista. $O$ teatro de temática científica propõe a mobilização dos recursos de iluminação, sonoplastia, cenografia, figurinos, performance de atores (voz, corpo etc.), dentre outros, para significação da ciência e da tecnologia.

\section{Opressão, libertação e a ciência}

Em sua delimitação de opressão, Freire $(1976,1987,1994)$ analisa o processo de desumanização a que povos e grupos sociais foram submetidos ao longo da história. A desumanização é o processo de negação do outro enquanto ser humano, enquanto ser que pensa, cria, constrói e que possui cultura, subjetividades, sonhos, potencialidades e direitos. Ela se concretiza no impedimento do ser mais de um determinado sujeito ou grupo social. $\mathrm{O}$ ser mais significa alcançar o máximo que a potencialidade de um determinado sujeito lhe permita atingir. Opressor é aquele que, em uma ação de violência, impede o oprimido de ser mais.

Importante ressaltar que para Freire (1987) a opressão provoca a desumanização tanto do oprimido quanto do opressor, uma vez que o conceito de humanização envolve a conscientização e o reconhecimento do outro enquanto igual, e por isso livre para pensar, criar e construir. Humanização e desumanização são possibilidades dos seres em sua inconclusão, 
entretanto, a vocação dos homens é a humanização. A desumanização seria o resultado de uma ordem injusta que gera a violência e o ser menos. A violência dos opressores impõe aos oprimidos o ser menos, levando-os à luta contra os primeiros.

A teoria da ação antidialógica (FREIRE, 1987) demonstra que o mecanismo de opressão envolve processos de conquista, de subjugação, de coisificação e de determinação do oprimido. São utilizadas as estratégias de divisão, que garantem a contraditória perspectiva de realidade na qual as minorias oprimem as maiorias; de manipulação, que anestesia as massas populares para que não pensem e, ao mesmo tempo, se conformem; e de invasão cultural, que é a penetração dos opressores no contexto cultural dos oprimidos, impondo sua visão de mundo enquanto thes freiam a criatividade.

A recuperação da humanização (do oprimido e do opressor) acontece quando os oprimidos se libertam em uma revolução cultural. Entretanto o processo de libertação é dificultado pelo fato de os oprimidos hospedarem as ideias do opressor em si mesmos, sendo necessário o reconhecimento como hospedeiros do opressor antes de libertar-se. No caminho do auto reconhecimento os oprimidos tendem a tornar-se opressores, uma vez que em sua vivência usufruir da humanidade é ser opressor. A libertação envolve também o medo da própria liberdade, decorrente da ausência da relação prescritiva da mediação opressor oprimido, na qual há imposição da visão de mundo da primeira consciência sobre a segunda. Esse medo decorre da insegurança da consciência hospedeira em criar sua pauta, com conteúdos que não os do opressor. O medo da liberdade também é sentido pelo opressor, decorrente da perda da "liberdade" de oprimir.

A revolução cultural (FREIRE, 1987) é necessária à dissipação da situação de opressão e à manutenção da não opressão. Ela é o máximo de esforço de conscientização, com a finalidade última de conscientizar a todos, e que resulta na reconstrução da sociedade e na superação da sociedade opressora. Entretanto, a revolução cultural não significa a troca de uma sociedade estática por outra igualmente estática, mas sim a chegada a um processo contínuo e permanente de libertação, no qual há o diálogo constante entre liderança e povo, legitimando a participação do povo nas instâncias de poder. Contrapondo-se à conquista e à ação antidialógica, a revolução cultural é alcançada e se mantém por meio da ação dialógica, caracterizada pela co-laboração, a união, a organização e a síntese cultural. Na co-laboração os sujeitos se encontram em igualdade para a transformação do mundo, mesmo que estes tenham funções ou responsabilidades distintas. Cabe a cada sujeito o desvelamento do mundo. E mesmo quando um sujeito inicia o esforço de desvelamento para os outros, é preciso que estes se tornem sujeitos do desvelar. Esse processo se desenvolve por meio do diálogo, da comunicação. A união dos oprimidos entre si é condição essencial para a revolução cultural. O estabelecimento da relação solidária resulta no reconhecimento de grupo, numa consciência 
de classe. Para que a união se efetive é necessário que os oprimidos cortem o cordão umbilical (mágico e mítico) que os ligam ao mundo da opressão.

Nesse contexto, a organização não é entendida como justaposição de indivíduos, mas sim como processo organizado de aprendizado da pronúncia do mundo, aprendizado dialógico. Se materializa no momento em que a liderança e o povo, juntos, instauram a transformação da realidade que os mediatiza. Implica em autoridade, não podendo ser autoritária, e em liberdade, não sendo licenciosa. Por fim, a síntese cultural pretende a superação da indução própria da ação antidialógica.

A síntese cultural pode decorrer da ação cultural. Esta última é uma forma sistematizada e deliberada de ação visando manter ou transformar a estrutura social vigente, podendo estar a serviço da dominação ou da libertação. A ação cultural assume caráter indutivo e prescritivo quando visa a dominação. Nesse caso o marco valorativo e ideológico dos dominadores prevalece, resultando em invasão cultural. É possível identificar atores (sujeitos que pensam e elaboram a ação cultural) e os espectadores (pessoas que recebem e assimilam a cultura imposta).

A síntese cultural é marcada pela ação cultural libertadora, na qual mesmo com os atores vindo de uma outra cultura o movimento é o de conhecer o povo e sua cultura, de integrar-se a ele e, ambos, em um processo dialógico, exercerem ação sobre o mundo. $\mathrm{Na}$ prática, na síntese cultural desaparece a dicotomia atores-espectadores e todos são reconhecidos como atores na transformação da realidade, visando a libertação dos homens e das mulheres. Há a superação da indução e, por conseguinte, da invasão cultural. Liderança e povo criam juntos as pautas para as ações. Importante frisar que a síntese cultural não implica na ilusão de que não haverá diferentes pontos de vista, seja entre liderança e povo, ou mesmo entre o próprio povo em si, mas sim no compromisso real e constante de que não haja invasão cultural nem de um lado nem de outro, e que constantemente se alcance sínteses a partir das diferentes perspectivas, das diferentes culturas. Ela tem como finalidade a síntese que serve à organização para a libertação.

A libertação só é alcançada com a mudança objetiva e concreta da opressão e não tão somente com o reconhecimento dela e com as decorrentes ações particulares e pontuais de solidariedade, que terminam por mascarar e manter a situação de opressão. Ela implica na imposição de freios aos antigos opressores para que não voltem a oprimir. E isto não se configura como opressão. Uma vez que opressão só existe quando se constitui em um ato proibitivo do ser mais dos homens, a proibição de um regime opressor, então, não se iguala ao que cria e mantém a opressão. Com a instalação de uma nova realidade inaugurada pelos oprimidos, os opressores de ontem não se reconheceriam em libertação. Isto se dá porque se constituíram na experiência de opressores, logo tudo o que não seja o seu direito antigo de 
oprimir significa opressão a eles. Para os opressores as pessoas humanas são apenas eles, os outros são coisas. Há o seu direito de viver em paz ante o direito dos outros de sobreviverem.

A partir da discussão apresentada, nesta investigação adotamos o conceito de opressão enquanto movimento em que um sujeito, ou grupo social, é impedido de ser mais. Isto é, em que lhe é negado o reconhecimento enquanto ser que pensa, cria e constrói, que possui cultura, subjetividades, sonhos, potencialidades e direitos. E em que ações culturais de dominação são realizadas para concretizar esse impedimento. As ações culturais de dominação envolvem processos de conquista, de subjugação, de coisificação e de determinação do oprimido. Na opressão se utiliza de estratégias de divisão, de manipulação e de invasão cultural.

No intuito de analisar as relações entre ciência e opressão, considerando a noção de opressão aqui adotada, recorremos ao conceito de campo científico cunhado por Bourdieu (1983; 2004). Esse autor analisa a ciência a partir de uma ótica sociológica e a entende como um campo social, o campo científico, que é um lugar de luta concorrencial pelo monopólio da competência científica (capacidade técnica e poder social), pela autoridade e legitimidade de se falar e agir na ciência.

Uma vez que as práticas científicas são orientadas para o incremento da autoridade científica, o interesse por uma atividade científica específica torna-se decorrente do interesse intrínseco (importante para o pesquisador) e do interesse extrínseco (importante para os outros pesquisadores), ambos indissociáveis. Nessa interação é que o campo científico define para cada pesquisador seus problemas de investigação, seus métodos e suas estratégias científicas que, em suma, são estratégias científicas e políticas ao mesmo tempo. Por esse prisma todas as escolhas científicas são entendidas como estratégias políticas orientadas para o lucro científico (reconhecimento entre os pares).

A luta pela autoridade no campo científico é marcada pelo fato de os pesquisadores do campo terem como clientes os seus concorrentes. Assim, um pesquisador particular só poderá obter reconhecimento do valor de suas pesquisas por seus concorrentes, que não o farão sem uma análise rigorosa. A atribuição de reconhecimento é dependente do valor distintivo dos produtos de pesquisa e da originalidade destes, entendidos como importante contribuição aos conhecimentos científicos já acumulados. Nessa dinâmica, o capital de autoridade é monopolizado pelo primeiro que faz a descoberta, ou o que a torna conhecida. Isso explica porque alguns pesquisadores precipitam-se na publicação de resultados iniciais.

O processo de reconhecimento pelos pares se acentua quanto mais autônomo for o campo, e nele está em disputa o poder de impor uma definição de ciência, que estará adequada aos seus interesses específicos. "Os dominantes são aqueles que conseguem impor uma definição da ciência segundo a qual a realização mais perfeita consiste em ter, ser e fazer 
aquilo que eles têm, são e fazem" (BOURDIEU, 1983, p. 128). Em última instância, são os princípios de avaliação da prática científica que estão em jogo na imposição de uma definição legítima de ciência. Pode-se identificar a opressão definida por Freire (1987) na relação entre cientistas dominantes e cientistas dominados no interior do campo científico, uma vez que o cientista (ou grupo) dominante impõe sua perspectiva do que seja ciência e de como se faz ciência.

A estrutura do campo científico se modifica dinamicamente pelas lutas entre os protagonistas (agentes ou instituições), sendo a distribuição do capital científico resultante das estratégias de conservação ou de subversão da própria estrutura (BOURDIEU, 2004). Ela pode variar entre dois limites teóricos: em um extremo a situação de monopólio do capital específico de autoridade científica por um sujeito ou instituição, e em outro a situação de distribuição equitativa do capital entre todos os concorrentes. Nela estão os dominantes (maior capital científico) e os dominados (menor capital científico). Os dominantes utilizamse de estratégias de conservação, visando perpetuar a ordem científica estabelecida, a qual não se reduz à ciência oficial (instrumentos, obras, hábitos científicos etc.), mas engloba também a manutenção das instituições que produzem e circulam os bens científicos e produzem os produtores e consumidores desses bens. Já os novatos podem utilizar as estratégias de sucessão, que favorecem o alcance do lucro científico por fundarem-se na realização da ciência oficial dentro dos limites autorizados, ou as estratégias de subversão, que implicam em investimentos mais arriscados e na modificação dos princípios de legitimação da dominação.

Estratégias de conservação, de sucessão e de subversão. Em uma leitura freireana esses conceitos construídos por Bourdieu explicitam o processo de dominação cultural e o impedimento do ser mais tanto dos cientistas novos quanto dos cientistas antigos que não possuem um grande capital científico: os cientistas dominantes se utilizam de estratégias de conservação (ação cultural dominadora) para a manutenção da ordem estabelecida; aos cientistas novatos e aos antigos sem capital científico cabe optar por estratégias sucessoras e aceitar (invasão cultural) e reproduzir a ciência conforme prescrita (abrindo mão de seu criar e construir) ou por estratégias de subversão (ação cultural libertadora, resultando em síntese cultural) que implicam na modificação do status quo científico. Na análise de Bourdieu sobre os limites teóricos da estrutura do campo científico, identifica-se em um dos extremos a situação de opressão (monopólio por um cientista ou instituição) e no outro a situação resultante da síntese cultural, na qual a liderança científica e outros cientistas se reconheceriam enquanto pesquisadores legítimos e, juntos, agiriam sobre o fazer científico e sobre a concepção do que seja a ciência (distribuição equitativa do capital entre todos os concorrentes). 
Conquanto o campo científico sofra influências do arbítrio social dos cientistas (interesses pessoais) de outros agentes ou instituições não científicas a lógica do campo impõe um desvio sistemático dos fins no qual a busca do interesse científico privado resulta em algo proveitoso para o progresso da ciência. Isto é, apesar dos interesses individuais o campo científico se autorregula de maneira que a resultante atenda a interesses mais coletivos:

A ordem coletiva da ciência se elabora na e pela anarquia concorrencial das ações interessadas, cada agente encontrando-se dominado - e, com ele, todo o grupo pelo entrecruzamento aparentemente incoerente das estratégias individuais (BOURDIEU, 1983, p. 144).

Enquanto o método científico e a censura que ele impõe não estão definidos no interior de um determinado campo as rupturas científicas tomam forma de revoluções contra as instituições, contra a ordem estabelecida. Porém, quando se tem um método consolidado, e não se recorre a subterfúgios estranhos ao campo, a revolução científica é chancelada por uma instituição que fornece as condições necessárias à ruptura. Nesse último caso, o campo tornase lugar de uma revolução permanente, porém sem efeito político. Nessa dinâmica, à medida que o método científico é assimilado pelos mecanismos sociais tornando-se lei social imanente, ele objetiva-se enquanto instrumento de dominação dos que o usam, produzindo controle e censura, mas também invenção e ruptura. Nos dois casos, a detenção de maior capital científico é o que possibilita com que determinado cientista (ou instituição) realize rupturas no método científico dominante, resultando na revolução científica.

Sob a ótica de Freire a revolução científica chancelada por uma instituição assemelhase a generosidade falsa (FREIRE, 1987), que é uma maneira de manter a ordem injusta e de se comprar a paz. Na generosidade falsa o opressor faz dos oprimidos objetos de seu humanitarismo, no qual não há verdadeira libertação e humanização, mas permanência de dependência e de subjugação, reforçando a opressão. Na revolução científica chancelada não há alteração na estrutura que sustenta a opressão. Há mudança, mas limitada e sem efetiva liberdade de pensar e autonomia dos cientistas dominados.

Bourdieu (1983) argumenta que o fundamento da ciência é a crença coletiva nos seus fundamentos, que são produzidos pelo campo científico por meio de práticas, dos problemas, dos métodos e das soluções consideradas científicas e dos mecanismos sociais de seleção dos pesquisadores. Entretanto, qualquer campo científico está localizado em um ponto entre o espaço teórico que vai do campo religioso - no qual a verdade é a imposição de um arbítrio cultural - ao campo científico que exclui qualquer elemento de arbitrário social, no qual se impõe as normas da razão. Assim as diferenças entre os campos científicos residem no grau de dependência às demandas externas (culturais). Contudo, é uma ficção pensar em uma ciência (ou campo científico neutro). 
As relações entre o campo científico e as demandas externas (culturais) trazem à tona uma dimensão de análise das relações entre a ciência e opressão que decorre da tensão com o arbítrio cultural. Nessa dimensão a ciência ora pode ser tida como libertadora, ora pode ser tida como opressora. Algumas situações podem explicitar essa dualidade. Auler (2007) sinaliza que no final do século XX passa a ser imputado aos cientistas um papel que representa, ao mesmo tempo, a esperança da solução de problemas e impasses e o risco de surgimento de novos problemas e impasses. Essa visão surgiu da percepção de que o avanço da ciência ao mesmo tempo poderia trazer melhorias (medicamentos, materiais etc.), mas também poderia provocar danos (organismos nocivos, degradação do meio ambiente etc.). De uma perspectiva, a ciência vista como libertadora, no sentido de possibilitar uma melhoria na saúde e no bem estar da população, o que tem impacto positivo para o ser mais, uma vez que condições facilitadas de existência favorecem a liberdade para pensar, criar e construir. De outra perspectiva, a mesma ciência, só que ciência opressora, devido a destruição de ecossistemas e de vida, o que dificulta e impede o ser mais.

Importante considerar a dimensão que toca a relação entre a ciência e o organismo fisiológico humano em si, da qual os conflitos resultam nas discussões em bioética (COSTA et al., 1998), abarcando reflexões sobre a necessidade de proteção do genoma humano e os problemas da discriminação genética e racismo (MACHADO, 2011). Novamente, de um lado a ciência é libertadora quando demonstra a não existência de diferentes raças humanas, contribuindo para que os diversos povos tenham garantidos e respeitados o seu direito de ser mais. E de outro a ciência pode ser vista como opressora por impedir a existência de seres humanos melhores geneticamente modificados.

Por fim, Fischmann (2008) aborda o contato entre a ciência e a religião, em especial quando se trata da legitimação do Estado laico, com repercussões para as pesquisas sobre células-tronco, a adoção de ensino religioso nas escolas públicas, a descriminalização do aborto, dentre outros temas. Nesse último exemplo a ciência pode aparecer como libertadora por reconhecer a existência das diferentes culturas e sociedades, na medida que marca a divisão entre Estado e pesquisa e religião e, com isso, favorece o direito às diferentes possibilidades de ser mais. Entretanto, para os religiosos, ela seria opressora, por não respeitar suas crenças e impedir que possam professar sua fé irrestritamente.

Em cada um desses exemplos a ciência pode ser tida ora ao lado da opressão ora ao lado da libertação, o que determinará esse enquadramento são os valores, os aspectos éticos e religiosos, os interesses econômicos ou as particularidades de determinado grupo social com o qual ela estará em contato. Nesta pesquisa adotamos como hipótese inicial que por estarem inseridos em um ambiente em que se atribui valor ao conhecimento científico, os estudantes do grupo investigado possuem vivências em conflitos referentes às relações entre ciência e 
opressão. Assim, a análise de nossos dados será permeada pela explicitação dos conflitos, da associação da ciência à opressão e pelo mapeamento das percepções.

\section{Caminho metodológico}

O objetivo desta pesquisa é identificar e caracterizar as percepções de um grupo de estudantes universitários sobre as relações entre ciência e opressão. Ela foi desenvolvida na perspectiva da Pesquisa Educacional Baseada em Artes (PEBA). A PEBA surgiu na década de 70, nos E.U.A., entretanto foi sistematizada no fim do século XX por Tomas Barone e Eliot Eisner (BARONE; EISNER, 1997; OLIVEIRA; CHARREU, 2016). Essa modalidade de investigação é marcada pela presença de abordagens estéticas que suscitam o processo investigativo, isto é, são mobilizados procedimentos artísticos (literários, cênicos, visuais, performativos etc.) para revelar aspectos da vivência dos pesquisadores, leitores, colaboradores, dentre outros. Oliveira e Charreu (2016) defendem que vem sendo utilizada em pesquisas em antropologia, sociologia e psicologia.

O que caracteriza a PEBA não é tão somente a inclusão de imagens, poesias, desenhos, teatro etc., para compor a pesquisa, mas o modo como as formas de representação artística se inserem na pesquisa. Trata-se de se estabelecer um outro modo de se relacionar com o investigado, da apropriação de um olhar próprio do artístico, que permita perceber o que não seria possível por meio de outras metodologias (SINNER et al, 2006; BURGE et al, 2016; BOLDEN, 2017).

A linguagem artística adotada nesta investigação foi o Teatro do Oprimido (TO). Essa escolha foi decorrente de o tema opressão ser foco de debate dessa modalidade de teatro. $\mathrm{O}$ objetivo do TO (BOAL, 2008; 2013) e de sua poética é transformar o espectador em sujeito (ator) no fenômeno teatral. Nele, o espectador assume o papel protagônico, transforma a ação dramática inicialmente proposta, ensaia soluções possíveis, debate projetos modificadores, preparando-se para a ação real.

Na perspectiva de Boal (2013) o teatro veio do povo e pertence ao povo, mais ainda, deve ser mobilizado pelo povo enquanto arma contra a sujeição artística e cultural decorrente da dominação econômica. A qual teria como finalidade a uniformização da cultura e do ser humano, difundindo um único modelo de ser e de existir, pautado nos princípios da classe economicamente dominante. A estética do oprimido tem sua origem na ética, na política, na história e na filosofia. O treinamento para a prática do TO inicia-se com jogos abordando a imagem, o som e a palavra, visando a desmecanização do corpo e da mente alienados às tarefas do dia a dia (BOAL, 2008), depois são trabalhadas as principais técnicas (Teatro Imagem, Teatro de Jornal, Arco-íris do Desejo, Teatro Fórum, Teatro Invisível, Ações Diretas e o Teatro Legislativo). Esta pesquisa foi desenvolvida utilizando a palavra, a imagem e o 
som como caminhos para que cada participante pudesse expressar suas concepções. No quadro 1 são apresentadas as principais atividades artísticas e seus objetivos para a pesquisa e na figura 1 são explicitadas as relações entre as atividades artísticas e a coleta de dados:

Quadro 1 - Principais atividades artísticas e seus objetivos para a pesquisa.

\begin{tabular}{|c|c|c|c|c|c|c|}
\hline $\begin{array}{c}\text { Teatro do } \\
\text { oprimido }\end{array}$ & \multicolumn{2}{|c|}{ Palavra } & \multicolumn{2}{c|}{ Imagem } & \multicolumn{2}{c|}{ Som } \\
\hline $\begin{array}{c}\text { Coleta dos } \\
\text { dados }\end{array}$ & Grupo focal & Músicas & Objetos & Desenhos & Músicas & Instrumentos \\
\hline Objetivo & $\begin{array}{c}\text { Explicitar as concepções } \\
\text { por meio da palavra. }\end{array}$ & $\begin{array}{c}\text { Explicitar as concepções } \\
\text { por meio da imagem. }\end{array}$ & $\begin{array}{c}\text { Explicitar as concepções por } \\
\text { meio de sons. }\end{array}$ \\
\hline
\end{tabular}

Fonte: Elaboração própria.

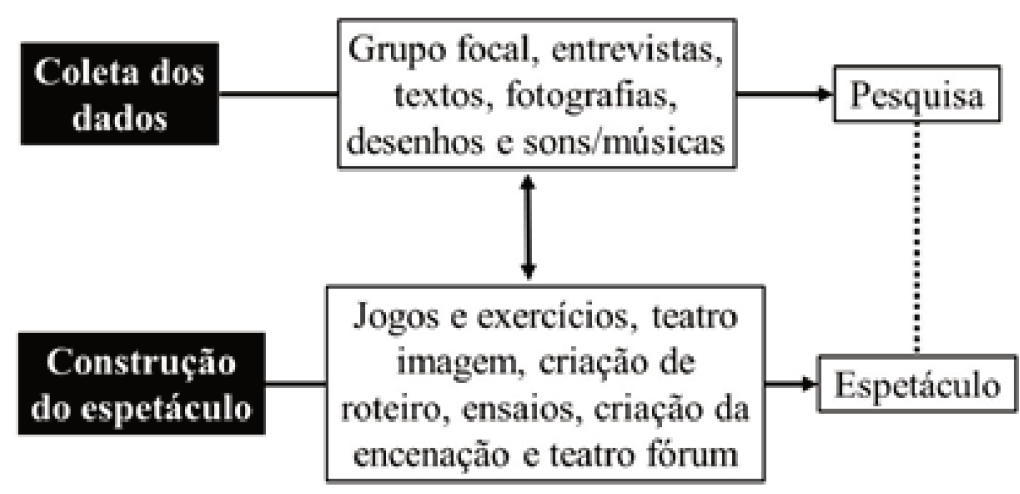

Figura 1 - Coleta de dados e construção da peça.

Fonte: Elaboração própria.

A coleta de dados aconteceu ao longo dos procedimentos de montagem de uma peça de Teatro Fórum, por meio de grupo focal com os colaboradores, jogos e exercícios teatrais, jogos de Teatro Imagem e Teatro Fórum. O grupo focal foi escolhido por ser uma técnica facilmente utilizada durante as conversas no grupo e por ser uma estratégia indicada para a elucidação da percepção de um grupo de pessoas sobre conceitos ou temas (GOMES, 2005). Os registros dos dados ocorreram por meio de fotografias, produção de textos, produção de desenhos e filmagem. As imagens apresentadas neste artigo fazem parte do acervo pessoal do pesquisador e sua divulgação foi autorizada pelos colaboradores. As atividades aqui descritas foram desenvolvidas no período de 8 meses, ao longo de dois encontros semanais, com três horas de duração cada.

Os colaboradores desta pesquisa foram nove estudantes de graduação, sendo quatro do curso de licenciatura em química, dois do curso de bacharelado em química, um do curso de engenharia e dois do curso de enfermagem. Esses estudantes estavam entre o quarto e o oitavo período de seus respectivos cursos de graduação e eram integrantes de um projeto de extensão 
universitária que tem como objetivo divulgar a ciência e a tecnologia por meio do teatro para adolescentes em idade escolar.

\section{Percepções sobre as relações entre ciência e opressão}

As atividades tiveram início com a realização de um grupo focal (GF), que teve como roteiro os questionamentos: Em sua opinião, a ciência oprime? Por que? e Você já se sentiu oprimido pela ciência? Cite uma situação em que a ciência te oprimiu. Outras questões complementares foram sendo inseridas ao logo do GF no intuito de se elucidar cada vez mais as ideias dos participantes. Inicialmente o grupo de estudantes se dividiu nos que classificaram a ciência em opressora e nos que a classificaram em não opressora. Porém, no decorrer das falas o grupo foi refletindo e caminhando para uma separação entre a ciência e o sujeito que a representa. Este último poderia se utilizar da ciência e ser um opressor, já a ciência em si não poderia ser qualificada como opressora ou não. Os trechos a seguir exemplificam a evolução dessas ideias:

\footnotetext{
Conhecimento pode gerar uma opressão, mas ele não é diretamente ligado à opressão, entendeu? Porque todo conhecimento pode ser usado "pro" bem ou "pro" mal [...]a ciência não oprime. Ela pode gerar opressão. Se todas as pessoas que tem a ciência, nenhuma delas oprimir, a ciência não oprime. Mas se uma dessas pessoas oprimir, a ciência oprime. (Colaborador 1)
}

O cara que utiliza a ciência de forma opressora, o cara utiliza o que ele sabe de conhecimento científico e ele é o opressor. Mas no caso, a ciência não está colocando uma qualidade, sabe, em alguma coisa que não tem uma qualidade de ser ou não. (Colaborador 2)

Eu acredito que a ciência em si, ela não, é, ela não é opressora, mas sim as pessoas que detém o conhecimento sobre ela, algumas vezes. (Colaborador 3)

A ciência é percebida como objeto, ou ferramenta, e quem a representa como sendo detentor do conhecimento científico é que pode se utilizar dessa ferramenta para oprimir ou libertar. Essa primeira reflexão do grupo vai ao encontro de Bourdieu (1983), quando este analisa a ciência a partir do conceito de campo científico e demonstra o quanto a atividade científica não é neutra, uma vez que decorre do interesse do pesquisador e do conjunto de pesquisadores. E que a negociação entre os interesses particulares e coletivos é que define os problemas de investigação e os métodos, sendo a ciência o resultado de estratégias científicas e políticas ao mesmo tempo. Essa concepção se manteve estável no grupo durante todo o processo de investigação, isto é, toda vez que se falou que a ciência oprime se estava dizendo que alguém utilizou o conhecimento científico para oprimir.

Após o primeiro momento, foi solicitado aos colaboradores que relatassem situações pessoais em que consideravam terem sido oprimidos pela ciência. As situações relatadas foram: ter o esforço não reconhecido ao fazer um trabalho difícil; ridicularização por meio de piadas feitas por um professor devido a não saber uma informação; negação de orientações 
sobre o comportamento apropriado a execução das atividades no laboratório; impedimento em escrever a opinião própria em um artigo; ser criticado por ser cristão; e negação de informações sobre a própria saúde. Considerando o conceito de opressão adotado nesta pesquisa, o não reconhecimento em fazer um trabalho difícil não se caracteriza como uma situação de opressão, uma vez que isso não implica em um impedimento concreto do ser mais. Ao contrário, as outras situações relatadas denotam estratégias de dominação (ridicularização e negação de orientação/informação), que englobam o não reconhecimento da cultura e da subjetividade do outro (religião), nas quais, "através da manipulação, as elites dominadoras vão tentando conformar as massas populares a seus objetivos" (FREIRE, 1987, p. 83).

Já no impedimento de se escrever a opinião em um artigo identifica-se, por um lado, a negação da criação e do pensar, e, de outro, a dinâmica do campo científico, em que, de acordo com Bourdieu (2004), os cientistas dominantes determinam a maneira com que se faz ciência e os novatos podem se submeter às estratégias de sucessão visando adquirir capital científico. Nesses últimos casos houve impedimento em ser mais.

Após a explicitação das concepções dos estudantes no grupo focal tiveram início procedimentos mais específicos do TO mobilizando a imagem, o som e a palavra. O papel do TO nesse processo foi o de fazer emergir aspectos da subjetividade dos estudantes que pudessem ter ficado encobertos no momento do GF. Guiados pelas premissas da PEBA (BARONE; EISNER, 1997; OLIVEIRA; CHARREU, 2016), o teatro foi a abordagem estética adotada para favorecer a explicitação de nuances da vivência dos colaboradores com respeito a relação entre ciência e opressão que ainda não havia emergido. Considerando os relatos dos colaboradores foi construído um roteiro que em sua versão final continha sete cenas (vide quadro 2).

Quadro 2- Roteiro do espetáculo.

\begin{tabular}{|c|l|c|l|}
\hline Cena & $\begin{array}{c}\text { Objetivo } \\
\text { (situação de opressão) }\end{array}$ & \multicolumn{1}{|c|}{ Música } & \multicolumn{1}{|c|}{ Ambiente } \\
\hline 1 & Obrigação de estudar & Química & Indefinido. \\
\hline 2 & Professor $\rightarrow$ aluno & - & Sala de aula. \\
\hline 3 & Condições de trabalho & Rodo cotidiano & Indefinido. \\
\hline 4 & $\begin{array}{l}\text { Enfermeira } \rightarrow \text { paciente } \\
\text { Médica } \rightarrow \text { enfermeira }\end{array}$ & - & Sala de espera. \\
\hline 5 & Mídia e manipulação & Admirável chip novo & Indefinido. \\
\hline 6 & Médico $\rightarrow$ paciente & - & Consultório. \\
\hline 7 & Disputa pelo poder & Summer overture & Indefinido. \\
\hline
\end{tabular}

Fonte: Elaboração própria. 
Nas cenas 2, 4 e 6 são apresentadas as opressões impostas aos colaboradores em que a ciência estava envolvida. Na cena 2 um professor desqualifica os argumentos dos estudantes sobre a forma com que ele ministra seu curso e se justifica dizendo que eles estão em uma universidade pública, de qualidade, que desenvolve pesquisas, e por isso a exigência é muito alta. A partir da leitura de Bourdieu (1983), essa cena denuncia o preço a ser pago pelo capital científico que se adquire ao se formar em uma universidade pública. $\mathrm{O}$ alto grau de cobrança, e as opressões decorrentes, são justificados pelo reconhecimento entre os pares que o estudante irá adquirir. E a perspectiva de alcance desse futuro promissor parece ser reforçada pela própria presença do professor universitário, que detém razoável capital científico.

Na cena 4, primeiro uma enfermeira nega a um paciente informação sobre a doença dele, privando-o do conhecimento científico sobre seu estado de saúde, e depois um médico desqualifica e expõe pejorativamente o trabalho de uma enfermeira, denotando que um conhecimento médico é superior a um conhecimento de enfermagem. No primeiro momento a cena exemplifica a postura arrogante relatada pelo professor 1. Em um segundo momento, considerando Bourdieu (2004), a cena coloca em evidência o conflito entre dois campos científicos próximos (enfermagem e medicina) e a luta pela legitimidade e autoridade sobre os conhecimentos científicos referentes à saúde. O que favorece as opressões presentes nessas cenas é, novamente, a diferença entre o capital científico dos sujeitos (médico, enfermeiro e paciente). Por exemplo, pode-se considerar que o capital científico do médico é maior do que o do enfermeiro, não porque um médico possua necessariamente mais conhecimentos científicos do que um enfermeiro, mas porque o capital simbólico atribuído à medicina pela tradição cultural é maior.

Por fim, na cena 6 , um médico desqualifica a crença religiosa de uma paciente argumentando que não há lugar para religião no tratamento da doença dela. Aqui é exemplificado o movimento de autorregulação e resistência ao arbítrio cultural (BOUDIEU, 1983). As cenas funcionaram como suporte que permitiu a explicitação e socialização das percepções do grupo de colaboradores, e ao mesmo tempo ilustraram análises identificadas em Freire (1987), no que se refere a contradição opressor-oprimido (professor-estudante, médico-enfermeiro, enfermeiro-paciente, médico-paciente) e às dinâmicas da situação de opressão, e em Bourdieu (2004), quanto ao uso do capital científico na manutenção da dominação na ciência.

As cenas foram construídas utilizando-se de exercícios do Teatro Imagem: primeiro os participantes utilizaram seus corpos para fazer uma imagem da situação de opressão (semelhante a estátuas); depois fez-se a imagem da situação ideal, sem opressão; e terminouse por fazer a imagem intermediária, que representa as ações que os envolvidos na situação de opressão deveriam realizar para acabar com a opressão (BOAL, 2008; 2009). Esse exercício 
foi permeado por discussões sobre o papel desempenhado pelos diversos sujeitos envolvidos em uma situação de opressão e em suas possibilidades de ação. Todas as imagens elaboradas nesse exercício foram incorporadas às cenas do espetáculo finalizado. Importante ressaltar que esse exercício é desenvolvido por meio de comunicação não-verbal, assim os colaboradores mostraram suas percepções sobre ciência e opressão corporalmente, sem o recurso da fala.

Em cada uma das cenas os colaboradores exemplificaram processos de desumanização e de alienação de sujeitos sendo impedidos de ser mais (FREIRE, 1987). A título de ilustração, na cena 1 , em que um professor oprime seus estudantes, a estratégia de dominação envolve a divisão dos estudantes, por meio de elogios excessivos aos que executam as tarefas e de desqualificação dos que não a realizam, e de manipulação, com a apresentação do professor como o detentor do conhecimento científico e modelo a ser seguido. No decorrer da cena os estudantes hospedam as ideias do professor e se convencem de que aquela é a maneira normal com que uma universidade pública de qualidade funciona, tornando-se alienados. A partir disso, deixam de questionar, pensar e criar e passam a se esforçar para realizar o que é prescrito pelo professor, desumanizados.

No processo artístico e científico que se realizou os colaboradores foram estimulados a explicitarem suas percepções por meio da imagem, do som e da palavra (BOAL, 2008; 2009), sendo os produtos das atividades incorporados ao espetáculo (vide figura 2). Por exemplo, na atividade em que foi solicitado aos colaboradores que elencassem objetos que representassem a relação entre ciência e opressão, foram indicados uma revista científica, a porta fechada da universidade, um crucifixo, um laptop, um colírio e um papel em branco. Na figura 2 é mostrado que o cenário do espetáculo foi composto por uma réplica das portas das salas de aula da universidade frequentada pelos colaboradores.

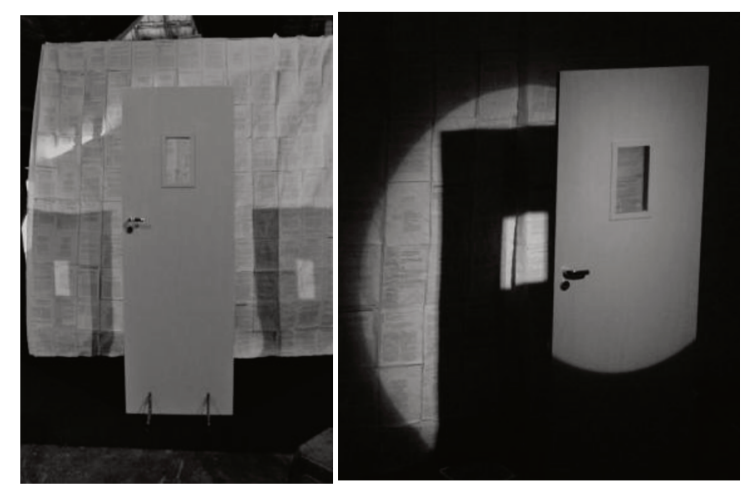

Figura 2 - Cenário da peça teatral.

Fonte: Acervo pessoal.

Essa referência à universidade que os estudantes frequentam também apareceu na atividade em que foi solicitado aos colaboradores a produção de um desenho que retratasse a opressão, vide figura 3 : 


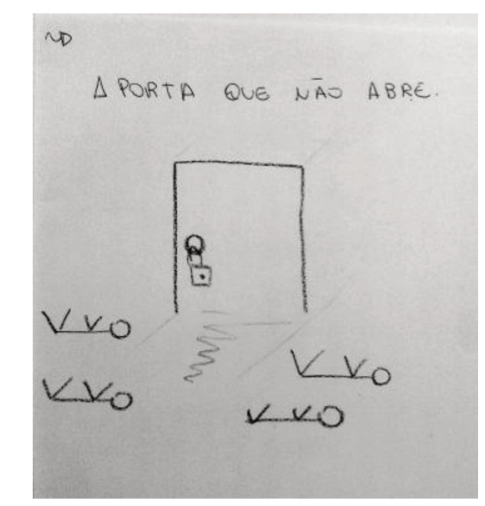

Figura 3 - Cenário da peça teatral.

Fonte: Acervo pessoal.

As discussões que levaram a escolha da porta como elemento do cenário envolveu a percepção da sala de aula enquanto lugar em que a ciência é utilizada para oprimir e de que a dificuldade em entrar na universidade (porta fechada) é decorrente de estruturas de opressão que inviabilizam o acesso à educação de qualidade a todos e todas. Outro importante elemento do cenário foi a cortina constituída por artigos científicos. Além de representar a situação de opressão vivenciada pelo colaborador 4, a presença desses artigos se destinou também a trazer à tona as discussões sobre a produtividade na academia e o capital científico atribuído ao paper.

Um objeto que merece destaque é o jaleco. Ele foi escolhido pelos colaboradores como representação da autoridade que possibilitava aos sujeitos utilizar a ciência para oprimir. O jaleco surge na primeira cena 1 de transição, quando é vestido pelo professor, depois é passado de opressor para opressor, durante as demais cenas de transição ( 3,5 e 7). Esse objeto parece materializar a ideia de capital científico, uma vez que quem o possuía adquiria a característica de poder oprimir. O jaleco é vestido pelos personagens que mais se apresentavam como opressores (professor e médico). Na figura 4 são ilustrados três momentos em que se expressa o significado do jaleco.
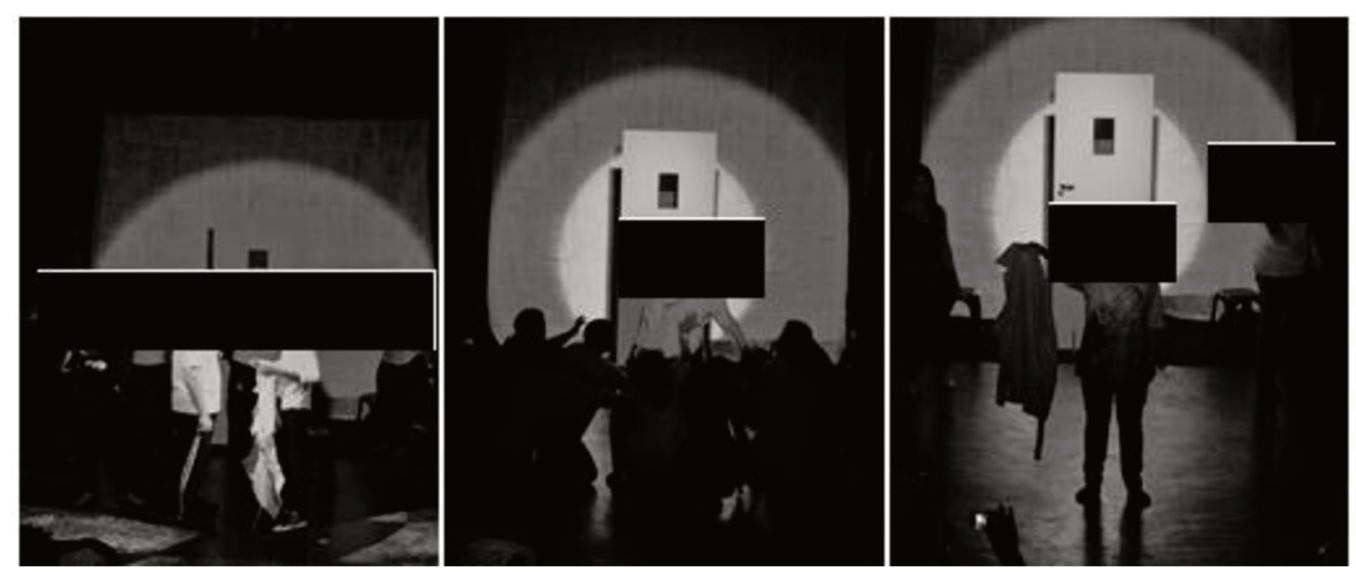

Figura 4 - O jaleco.

Fonte: Acervo pessoal. 
No primeiro recorte, o jaleco é passado entre dois atores que interpretam médicos. Ao entregar o jaleco para o segundo médico, o primeiro médico reconhece o segundo como autoridade e poder e saí de cena amedrontado. No segundo recorte o jaleco é disputado pelos personagens da peça, que se movimentam como animais, ao final ele é arrancado do ator que o vestia. No terceiro recorte é mostrado o momento final do espetáculo, em que uma das atrizes convida os espectadores a entrarem na disputa pelo jaleco, oferecendo-o para a plateia. A partir da indicação do jaleco e de suas aparições ao longo do espetáculo, é possível inferir que na percepção dos colaboradores ele materializa o poder e autoridade tomados pelo opressor, sendo objeto de desejo tanto de opressores quanto dos oprimidos.

Nas atividades com sons, além dos jogos e exercícios do TO, foram realizadas duas atividades direcionadas ao aprofundamento sobre a percepção dos colaboradores da relação ciência e opressão e à elaboração do espetáculo. Na primeira foram disponibilizados aos colaboradores instrumentos musicais (chocalhos, flauta de madeira, cajón, triângulo, xequerê, dentre outros) para que criassem o som da opressão. Na segunda, foi solicitado que cada colaborador escolhesse uma música que para ele simbolizasse a opressão. As músicas escolhidas foram Química, da Legião urbana; Rodo Cotidiano, d'O Rappa; Summer Overture, de Clint Mansel; Terra de gigantes, do Engenheiros do Hawai; Som de sirene; Air, de Bach; e Admirável Chip Novo, da Pitty.

A análise da letra das canções permite inferir sobre as relações construídas pelos colaboradores no movimento de reflexão e elucidação de suas percepções. Carvalho (2012) explica que a música Química, utilizada na cena 1, foi considerada o grito de guerra dos vestibulandos, oprimidos pela imposição de um modelo de vida e de educação. Na canção há um conflito geracional entre os pais (que querem garantir um futuro profissional para filho) e os jovens (que tem de abrir mão da sua juventude por um futuro incerto):

\footnotetext{
Estou trancado em casa e não posso sair / Papai já disse, tenho que passar / Nem música eu não posso mais ouvir / $E$ assim não posso nem me concentrar [...] Não posso nem tentar me divertir / O tempo inteiro eu tenho que estudar / Fico só pensando se vou conseguir / Passar na porra do vestibular [...] Chegou a nova leva de aprendizes / Chegou a vez do nosso ritual / E se você quiser entrar na tribo / Aqui no nosso Belsen tropical / Ter carro do ano / TV a cores / Pagar imposto / Ter pistolão / Ter filho na escola / Férias na Europa / Conta bancária / Comprar feijão / Ser responsável / Cristão convicto / Cidadão modelo / Burguês padrão / Você tem que passar no vestibular / Você tem que passar no vestibular / Você tem que passar no vestibular / Você tem que passar no vestibular (LEGIÃO URBANA, 1986. Grifo nosso.).
}

A ideia de uma opressão decorrente do sistema de educação apareceu também no desenho sobre opressão de um dos colaboradores (figura 5), no qual estava escrito educação opressora: 


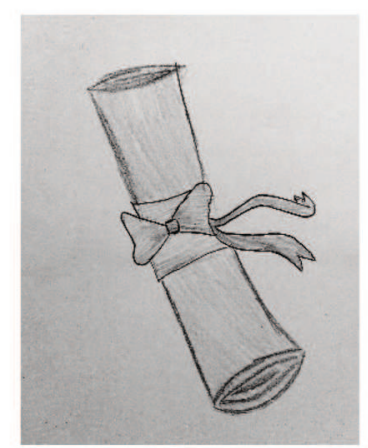

Figura 5 - O jaleco.

Fonte: Acervo pessoal.

Já a música Rodo Cotidiano, utilizada na cena 3, sugere a articulação com opressões que subjugam e submetem trabalhadores pobres e estigmatizados da cidade do Rio de Janeiro - utilizadores dos trens da Central do Brasil - a condições de desumanização:

Espaço é curto, quase um curral / Na mochila amassada, uma quentinha abafada / Meu troco é pouco, é quase nada / Meu troco é pouco, é quase nada [...] Não se anda por onde gosta / Mas por aqui não tem jeito, todo mundo se encosta / Ela some é lá no ralo de gente / Ela é linda, mas não tem nome / É comum e é normal / Sou mais um no Brasil da central / Da minhoca de metal que corta as ruas (LOBATO et al, 2003. Grifo nosso.)

Segundo Magalhães (2013), a canção Rodo Cotidiano tem como tema as classes populares, o operário anônimo, os subempregados, e traz à tona as mazelas sociais, denunciando a urgência da inclusão de quem vive à margem da sociedade. Essa associação com a opressão no âmbito das relações de trabalho também esteve presente no desenho produzido por um dos colaboradores (figura 6), denotando condições de escravidão:

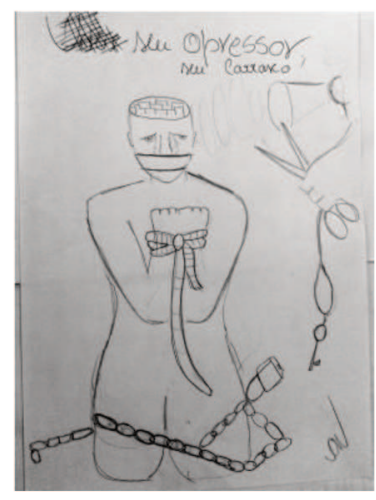

Figura 6 - O jaleco.

Fonte: Acervo pessoal.

Na análise de Franz (2007) a música Terra de Gigantes retrata o sentimento de desilusão da juventude dos anos de 1980 com a política, a pobreza, a miséria, a corrupção e a violência no Brasil. A canção traduz a passividade e o sentimento de impotência da juventude submetida a situação opressora imposta à população brasileira. 


\begin{abstract}
Hey, mãe! / Eu tenho uma guitarra elétrica / Durante muito tempo isso foi tudo / Que eu queria ter / Mas, hey mãe! / Alguma coisa fícou pra trás / Antigamente eu sabia exatamente o que fazer [...] Mas agora, lá fora / Todo mundo é uma ilha /A milhas e milhas e milhas / De qualquer lugar / Nessa terra de gigantes / Eu sei, já ouvimos tudo isso antes / A juventude é uma banda / Numa propaganda de refrigerantes / As revistas, as revoltas, as conquistas / Da juventude são heranças / São motivos pras mudanças de atitude / Os discos, as danças, os riscos / Da juventude / A cara limpa, a roupa suja / Esperando que o tempo mude [...] Hey, mãe! / Já não esquento a cabeça / Durante muito tempo / Isso foi só o que eu podia fazer [...] Nessa terra de gigantes / Que trocam vidas por diamantes / A juventude é uma banda / Numa propaganda de refrigerantes / Nessa terra de gigantes / Que trocam vidas por diamantes / A juventude é uma banda / Numa propaganda de refrigerantes (GESSINGER, 1998. Grifo nosso).
\end{abstract}

Outra nuance de opressão é acrescentada com a música Admirável Chip Novo, utilizada na cena 5. De acordo com Guadalupe, Padovani e Cosme (2014), a música da cantora Pitty faz referência ao livro Admirável Mundo Novo, de Aldous Huxley e transpõe para a segunda metade do século XX discussões que o livro apresentou em 1932. Ela problematiza uma opressão da era da computação e da comunicação, marcada pela imposição de comportamentos e condutas que impedem a reflexão sobre a própria condição humana. A crítica recai sobre o capitalismo e em suas relações de poder que condicionam à realização de ações, fazendo com que se perca a individualidade e com que se manipule pelo consumo.

Pane no sistema, alguém me desconfigurou / Aonde estão meus olhos de robô? / Eu não sabia, eu não tinha percebido / Eu sempre achei que era vivo / Parafuso e fluido em lugar de articulação / Até achava que aqui batia um coração / Nada é orgânico, é tudo programado / E eu achando que tinha me libertado / Mas lá vêm eles novamente, eu sei o que vão fazer / Reinstalar o sistema / Pense, fale, compre, beba / Leia, vote, não se esqueça / Use, seja, ouça, diga / Tenha, more, gaste, viva / Pense, fale, compre, beba / Leia, vote, não se esqueça / Use, seja, ouça, diga / Não, senhor, sim, senhor / Não, senhor, sim, senhor (PITTY, 2003. Grifo nosso).

Ao indicar essas músicas como representativas de suas percepções os colaboradores dão coro às discussões que elas trazem consigo. De fato, nas conversas que permearam a indicação das músicas e montagem de cenas houve ecos que corroboram a interpretação dos autores supracitados. Assim que, na segunda cena da peça, os personagens estudantes criticam o que denominam de sistema educacional opressor, que exige deles um comportamento específico por estarem em uma universidade pública; na quarta cena, a enfermeira se vê oprimida por condições de trabalho que inviabilizam a qualidade em sua atuação; e que na sexta cena a paciente se vê oprimida por uma abordagem desumanizada, que impõe o que ela deve pensar sobre religião, em uma tentativa de programá-la. De outro lado, e de maneira complementar, as músicas instrumentais (Summer Overture e Air) e som de sirene evocados tendem a demonstrar tonalidades de tensão, de lamento e de perigo relacionadas ao tema. Na figura 7 são apresentadas imagens das três principais situações de opressão relacionadas a 
ciência que são abordadas no espetáculo: cena 2 , Professor $\rightarrow$ aluno; cena 4 , enfermeira $\rightarrow$ paciente e médica $\rightarrow$ enfermeira; e cena 6 , médico $\rightarrow$ paciente.
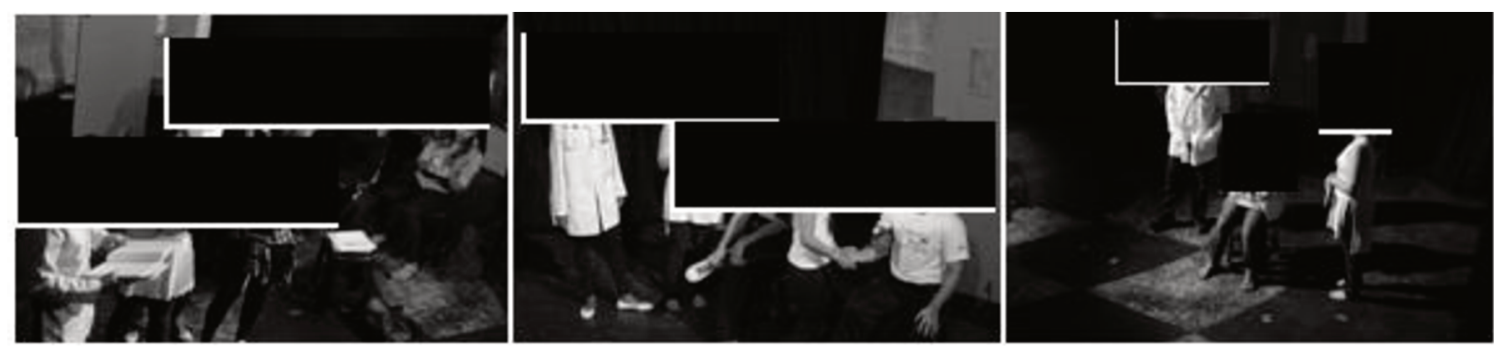

Figura 7 - Cenas 2, 4 e 6

Fonte: Acervo pessoal.

\section{Considerações finais}

A pesquisa aqui apresentada teve como objetivo identificar as percepções de um grupo de estudantes universitários sobre as relações entre ciência e opressão. Para isso, foi desenvolvida nos contornos da pesquisa educacional baseada em artes, tendo como linguagem artística o Teatro do Oprimido.

A partir da análise dos dados podemos inferir que, na percepção dos colaboradores, não existe uma relação direta entre ciência e opressão: a ciência pode ser utilizada para oprimir. O que caracteriza a opressão por meio da ciência é a sua legitimação pelo poder que é atribuído ao detentor da ciência, que decorre do fato de ele possuir capital científico. No caso da vivência dos colaboradores os representantes da ciência são os professores universitários. É no contato com os professores universitários (dominadores no campo) que os estudantes (novatos no campo) podem adquirir o capital científico necessário a uma possível carreira de sucesso. Porém, o preço a ser pago é a adoção dos hábitos próprios do campo científico, o que implica na supressão das subjetividades (aspectos culturais) e na adoção de uma ontologia e uma epistemologia próprias do campo científico. Nos procedimentos artísticos os colaboradores mostraram que em suas percepções a ideia de opressão por meio da ciência possui características comuns com outras formas de opressão, com destaque para as opressões impostas pelo mundo do trabalho, pela mídia e pelo sistema de educação. Foram explicitadas as similaridades dos mecanismos de opressão e o peso e o impacto que ela exerce sobre suas vidas e suas subjetividades.

Os resultados encontrados sugerem que o tema controverso ciência e opressão gera discussões que podem favorecer o conhecimento dos estudantes sobre o campo científico (sua estrutura, seu funcionamento e seus hábitos). Esse conhecimento é importante para que os estudantes tenham maior consciência dos conflitos que enfrentarão em suas formações acadêmicas e estabeleçam qual a melhor estratégia (subversão ou sucessão) a seguir. Também pode auxiliar em uma atitude positiva frente a ciência, uma vez que o entendimento de seu 
funcionamento permite procurar interseções entre os interesses pessoais e os interesses científicos.

A adoção do método Pesquisa Educacional Baseada em Artes - tendo o Teatro do Oprimido como linguagem estética - foi eficiente para o alcance do objetivo da investigação por ter possibilitado a explicitação de nuances das concepções dos colaboradores que não surgiram na discussão no grupo focal. Com a realização das atividades teatrais foi possível a visualização de um espectro amplo de associações decorrente do processo artístico em si. Nelas, para além da verbalização, a opressão no contexto da ciência e da tecnologia pôde tomar forma, ser objetificada (jaleco, artigo científico, diploma, porta fechada etc.) e ouvida (músicas instrumentais e escolha do estilo rock para as músicas com letra).

A pesquisa apresentada contribuiu para o campo de pesquisa em educação em ciências por exemplificar a aplicação da PEBA no contexto brasileiro, utilizando o teatro, e para a educação em ciências por fornecer análises que podem auxiliar para a mudança de posturas quanto a opressão nas ciências e para a ressignificação das relações na educação superior, podendo resultar em atitudes mais positivas frente a ciência e a tecnologia e estimular o maior envolvimento de estudantes em práticas científicas (POZZO; CRESPO, 2009). A formação dos estudantes durante nosso processo foi marcada pela conscientização sobre a opressão na ciência e as estratégias de dominação e de libertação utilizadas no campo científico. Isso pode ter os instrumentalizado para transitar no campo científico e para optar, conscientemente, por utilizar a ciência e a tecnologia para libertar ou oprimir.

Apesar de não ter sido foco desta investigação, houve indícios de que as concepções sobre as relações entre ciência e opressão dos colaboradores foram se modificando ao longo do processo. Entretanto, avaliamos que seria necessário um acompanhamento individualizado e sistematizado dos colaboradores para o mapeamento das mudanças. Essa é uma limitação deste estudo.

Ao final desta investigação foi produzido o espetáculo Imutável? no formato de Teatro Fórum (BOAL, 2009). Foram realizadas apresentações da peça na íntegra no Centro Cultural Rinha das Artes - Macaé no X Ciência em Cena - Salvador. Houve apresentações da cena 4 na disciplina de graduação Educação Alimentar e Nutricional III, do curso de graduação em Nutrição da Universidade Federal do Rio de Janeiro - Campus Macaé, ocasião em que o fórum foi centrado em discussões sobre opressão e trabalho em saúde. Com isso, tanto o objetivo da pesquisa quanto o objetivo do projeto de extensão foram alcançados.

\section{Referências}

AULER, D. Enforque ciência-tecnologia-sociedade: pressupostos para o contexto brasileiro. Ciência \& Ensino, v. 1, número especial, p. 1-20, 2007. 
BARBACCI, S. From the golem to artificial intelligence: science in the theatre for an existential reflection. Journal of Science Communication, v. 1, n. 3, p. 1-26. 2002.

BARONE, T; EISNER, E. Arts-based educational research. Complementary methods for research in education, v. 2, p. 75-116, 1997.

BOAL, A. Jogos para atores e não-atores. Rio de Janeiro: Civilização Brasileira, 2008.

BOAL, A. Teatro do oprimido e outras poéticas políticas. Rio de Janeiro: Civilização Brasileira, 2013.

BOLDEN, B. Music as Method: Musically Enhanced Narrative Inquiry. International Journal of Education \& the Arts, v. 18, n. 9, p. 1-19, 2017.

BORGERDING, L. A.; DAGISTAN, M. Preservice science teachers' concerns and approaches for teaching socioscientific and controversial issues. Journal of Science Teacher Education, v. 29, n. 4, p. 283-306, 2018.

BOURDIEU, P. Para uma sociologia da ciência. Lisboa: Edições 70, 2004.

BOURDIEU, P. O campo científico. In: ORTIZ, R. Pierre Bourdieu: sociologia. São Paulo: Ática, 1983. p. 122-155.

BURGE, A.; GODINHO, M. G.; KNOTTENBELT, M; LOADS, D. "...but We Are Academics!" A Reflection on Using Arts-Based Research Activities with University Colleagues. Teaching in Higher Education, v. 21, n. 6, p. 730-737, 2016.

CAMPANINI, B. D.; ROCHA, M. B. O teatro científico como estratégia didática para o ensino de ciências nas instituições de pesquisa pelo Brasil. Revista Ciências \& Ideias, v. 9, n. 3, p. 140-152, 2018.

CARVAlHo, E. F. de. Para além de uma história cultural do vestibular: elementos socioeconômicos em "Química" e "O pequeno burguês". Revista de História da UEG, v.1, n.1, p. 183-203, 2012.

CHEMI, T.; KASTBERG, P. Education through theatre: Typologies of Science Theatre, Applied Theatre Research, v. 3, n 1, p. 53-65, 2015.

COSTA, S. I. F.; OSELKA, G.; GARRAFA, V. Iniciação a bioética. Brasília: Conselho Federal de Medicina.

FISCHMANN, R. Ciência, tolerância e estado laico. Ciência e Cultura, v. 60, n. especial, p. 42-50, 2008.

FRANZ, J. P. dos R. Mapas do acaso: as canções de Humberto Gessinger sob a ótica contemporânea. Dissertação de mestrado em Letras. Universidade Federal do Rio Grande do Sul - Porto Alegre, 2007.

FREIRE, P. Pedagogia do oprimido. Rio de Janeiro: Paz e Terra, 1987.

FREIRE, P. Educação como prática para a liberdade. Rio de Janeiro: Paz e Terra, 1976.

FREIRE, P. Pedagogia da esperança. Rio de Janeiro: Paz e Terra, 1994. 
GESSINGER, H. Terra de gigantes. A revolta dos Dândis. Nova York: BMG, 1987. 1 CD. Faixa 2.

GOMES, A. Apontamentos sobre a pesquisa em educação: usos e possibilidades do grupo focal. Eccos Revista Científica, v. 7, n. 2, p. 275-290, 2005.

GUADALUPE, A. S. D.; PADOVANI, L. Z; COSME, A. L. F. Onde estão meus olhos de robô? O olhar sobre consumismo em Pitty e Caio Fernando. Revista Leitura, v. 2, n. 54, p. 179-192, 2014.

LEGIÃO URBANA. Química. Dois. Londres: EMI, 1986. LP. Lado B. Faixa 7.

LOBATO, M.; FALCÃO, M.; FARIAS, L.; XANDÃO; LOBATO, M. Rodo cotidiano. O silêncio q precede o esporro. Nova York: Warner Music, 2003. 1 CD. Faixa 4.

MACHADO, J. A. L. da S. Ciência, genoma e direitos humanos: reflexões na perspectiva de uma bioética da libertação. O Direito Alternativo, v. 1, n. 1, p. 34-60, ago. 2011.

MAGALHÃES, C. A. Cenas urbanas de mobilidade e de desterritorialização nas canções de O Rappa. Navegações, v. 6, n. 1, p. 105-113, 2013.

MARTINS, A. F. P. Natureza da Ciência no ensino de ciências: uma proposta baseada em "temas" e "questões". Caderno Brasileiro de Ensino de Física, v. 32, n. 3, p. 703-737, 2015.

MOREIRA, L. M.; MARANDINO, M. Teatro de temática científica: conceituação, conflitos, papel pedagógico e contex to brasileiro, Ciência \& Educação, v. 21, n. 2, p. 511-523, 2015.

OLIVEIRA, M. O. de; CHARREU, L. A. Contribuições da perspectiva metodológica 'investigação baseada nas artes'e da a/r/tografia para as pesquisas em Educação. Educação em Revista, v. 32, n. 1, p. .365-382, 2016.

POZO, J. I.; CRESPO, M. A. G. A aprendizagem e o ensino de ciências: do conhecimento cotidiano ao conhecimento científico. Porto Alegre: Artmed, 2009.

PITTY. Admirável chip novo. Admirável chip novo. Rio de Janeiro. Deckdisc, 2003. 1 CD. Faixa 2.

RAZERA, J. C. C.; NARDI, R. Ética no ensino de ciências: responsabilidades e compromissos com a evolução moral da criança nas discussões de assuntos controvertidos. Investigações em Ensino de Ciências, v. 11, n. 1, p. 53-66, 2006.

REIS, P. R. Ciência e Controvérsia. Revista de estudos universitários, v. 35, n. 2, p. 09-15, 2009.

REIS, D. A. dos; SILVA, L. F.; PINA, A. Algumas Compreensões de Licenciandos em Física Sobre o Fenômeno das Mudanças Climáticas. Alexandria: Revista de Educação em Ciência e Tecnologia, v.4, n.2, p.57-81, 2011.

REIS, N. A. dos; MOREIRA, L. M.; SILVA, E. L. da. Teatro, experimentação e divulgação científica na educação básica: uma tríade possível para a alfabetização científica. Revista de Ensino de Ciências e Matemática, v. 10, n. 1, p. 209-227, 2019. 
RIBEIRO, T. V.; SANTOS, A. T.; GENOVESE, L. G. R. A história dominante do movimento CTS e o seu papel no subcampobBrasileiro de pesquisa em ensino de ciências CTS. Revista Brasileira de Pesquisa em Educação em Ciências, v. 17, n. 1, p. 13-43, 2017.

SILVA, L. F.; CARVALHO, L. M. A temática ambiental e o processo educativo: o ensino de física a partir de temas controversos. Ciência \& Ensino, v. 1, n. especial, p. 1-12, 2007.

STRIEDERA, R. B.; KAWAMURA, M. R. D. Educação CTS: Parâmetros e Propósitos Brasileiros STS Education: Brazilian Parameters and Educational Purposes. Alexandria: Revista em Educação em Ciência e Tecnologia, Florianópolis, v. 10, n. 1, p. 27-56, 2017.

SINNER, A.; LEGGO, C.; IRWIN, R. L.; GOUZOUASIS, P.; GRAUER, K. Arts-Based Educational Research Dissertations: Reviewing the Practices of New Scholars. Canadian Journal of Education, v. 29, n. 4, p. 1223 - 1270, 2006.

\section{SOBRE OS AUTORES}

LEONARDO MACIEL MOREIRA. Licenciado em Química pela Universidade Federal de Juiz de Fora, mestre em Ensino de Ciências e Doutor em Educação pela Universidade de São Paulo. Professor Adjunto na área de ensino de química na Licenciatura em Química do Campus Macaé da Universidade Federal do Rio de Janeiro. Desenvolve pesquisas sobre a interface Educação, Ciências e Arte e sobre Educação em Ciências e Educação para Relações Étnico-raciais. Orienta mestrado e doutorado no Programa de Pós-Graduação em Educação em Ciências e Saúde (NUTES-UFRJ) e no Programa de Pós-graduação em Ensino de Química (IQ-UFRJ). Coordena o Projeto Ciênica (www.projetocienica.com.br).

ANGÉLICA SANTANA DO NASCIMENTO. Bacharel em Química pela Universidade Federal do Rio de Janeiro. Foi estagiária de extensão universitária no Projeto Ciênica.

LAISE NOVELLINO NUNES DE SOUZA. Bacharel em Engenharia Civil pela Universidade Federal do Rio de Janeiro. Foi estagiária de extensão universitária no Projeto Ciênica.

Recebido: 18 de setembro de 2018.

Revisado: 02 de junho de 2019.

Revisado: 18 de julho de 2019.

Aceito: 12 de setembro de 2019. 